\title{
Pengaruh Gaya Lift Terhadap Sudut Serang Airfoil Naca 0013 dengan Ansys Fluent
}

\author{
M. Fajri Hidayat*, Yos Nofendri \\ Program Studi Teknik Mesin \\ Universitas 17 Agustus 1945 Jakarta \\ ${ }^{1)}$ Email : fajri.hidayat@uta45jakarta.ac.id
}

\begin{abstract}
Abstrak - Dunia Kedirgantaraan di Indonesia yang semakin lesu, butuh Peneliti-peneliti bertalenta di bidang Aerodinamika agar bisa mengangkat kembali nama baik dan harga diri Bangsa. Penelitian saya kali ini bertemakan studi bidang aerodinamika dari potongan melintang sayap pesawat terbang type Airfoil NACA 0013 dengan mencari sudut serang yang tepat untuk Take Off. Tujuan Penelitian ini adalah untuk menentukan sudut serang terbaik dari Pesawat saat Take Off. Metode yang saya gunakan dengan penerapan Simulasi CFD menggunakan Software ANSYS-Fluent versi 14.5 dengan Workbench. Hasil yang di dapat dari penelitian ini akan ditabulasikan dalam tabel dan grafik hubungan antara Gaya Lift terhadap Sudut Serang. Dengan mengambil variabel sudut serang sebanyak 9 variabel yaitu $0^{\circ}, 3^{\circ}, 6^{\circ}, 9^{\circ}, 12^{\circ}, 15^{\circ}, 18^{\circ}, 21^{\circ}$, dan $24^{\circ}$. Dari hasil Simulasi didapat Sudut Serang terbaik untuk tipe NACA 0013 adalah $21^{\circ}$ dengan harga Gaya Lift sebesar 61,650 N.
\end{abstract}

Kata kunci: Airfoil NACA 0013, Gaya Lift, Sudut Serang

\begin{abstract}
The aerospace world in Indonesia is increasingly lethargic, it takes talented researchers in the field of Aerodynamics in order to reestablish the good name and dignity of the Nation. My research this time aims the field of aerodynamics of the cross section of airfoil aircraft wing type NACA 0013 by finding the right angle of attack for Take Off. The method I use with the application of CFD Simulation using Software ANSYS-Fluent version 14.5 with Workbench. The results obtained from this study will be tabulated in the table and graph of the relationship between the Lift to the Angles of Attack. By taking variable angle of attack as much as 9 variables that is $0^{\circ}, 3^{\circ}, 6^{\circ}, 9^{\circ}, 12^{\circ}, 15^{\circ}, 18^{\circ}, 21^{\circ}$, and $24^{\circ}$. From the Simulation results obtained the best angle of attack for the type of NACA 0013 is $21^{\circ}$ with the price of Lifting Force of 61,650 N.
\end{abstract}

Keyword: Aerospace, Airfoil NACA 0013, Angle of Attack, ANSYS Fluent, Lift

\section{Pendahuluan}

Yang melatar belakangi penelitian saya kali ini adalah butuhnya referensi penerbangan pesawat dalam hal pengambilan sudut serang. Penelitian ini berawal dari seringnya saya bereksperimen langsung menggunakan model sayap pesawat seri NACA yang saya modifikasi dengan menggunakan alat laboratorium Wind Tunnel. Beranjak dari itu saya mulai beralih menggunakan pendekatan simulasi CFD dengan ANSYS-Fluent.

Batasan masalah yang saya ambil dalam penelitian ini adalah sudut serang airfoil NACA 0013 terhadap garis horizontal sebesar $0^{\circ}, 3^{\circ}, 6^{\circ}, 9^{\circ}, 12^{\circ}, 15^{\circ}, 18^{\circ}, 21^{\circ}$, dan $24^{\circ}$.

Penelitian sebelumnya dilakukan Oleh

Musavir Bashir, S.A. Khan, Qummare Azam, Ayub Ahmed Janvekar ${ }^{[11]}$ yaitu tentang sudut serang sayap pesawat type NACA 4 Digit dengan seri yang berbeda.

Penelitian terdahulu juga dilakukan oleh Kang Pyo Cho, Seung Hwan Jeong, Dany Perwita Sari ${ }^{[10]}$ yang membahas pengaruh gaya Lift terhadap sudut serang Pesawat terbang NACA 4 Digit Seri yang berbeda juga.

Penelitian lain yang serupa dilakukan secara experimental pada wind tunnel dengan variasi kecepatan input yang dilakukan oleh James Julian, Harinaldi, Budiarso, Revan Difitro, Parker Stefan ${ }^{[9]}$.

\section{Dasar Teori}

Perumusan Dimensi NACA 0013 yang diambil dari buku "Theory of Wing Sections" Langkah selanjutnya dari data tersebut diatas dapat dibut dengan menggunakan Perumusan lainnya yang digunakan dalam penelitian ini adalah menghitung gaya Lift dengan perumusan sebagai berikut :

$$
C_{L}=\frac{L}{\frac{1}{2} \rho U^{2} A}
$$


Dengan $C_{L}$ adalah Koefisien Lift, L adalah Gaya Lift dan $\rho$ adalah Massa Jenis Fluida serta U adalah Kecepatan input uadara masuk wind tunnel dan A adalah Luasan Penampang Sayap Pesawat NACA 0013 sejajar sumbu horizontal. Perumusan diatas seperti yang tercantum dalam Textbook Fluid Mechanics, Frank M. White ${ }^{[1]}$. oleh Abbott Ira ${ }^{[5]}$ mengikuti aturan sebagai berikut :

\section{$Y_{t}=5 t\left[0,2969 X^{1 / 2}-0,1260 X-0,3516 X^{2}+0,2843 X^{3}-\right.$ $\left.0,1015 X^{4}\right]$}

Microsoft Excel dalam koordinat XY sebagai berikut :

Dimensi Actual Model Airfoil NACA

0013 Dengan Panjang Chord $250 \mathrm{~mm}$

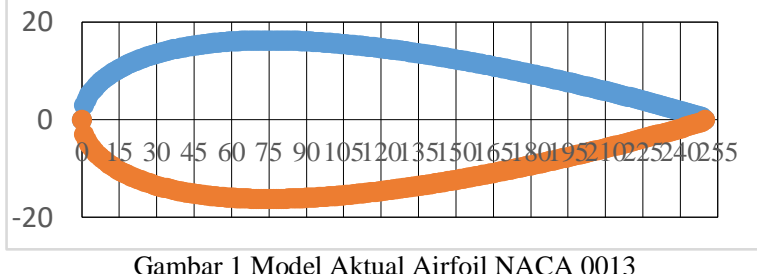

Gambar 1 Model Aktual Airfoil NACA 0013

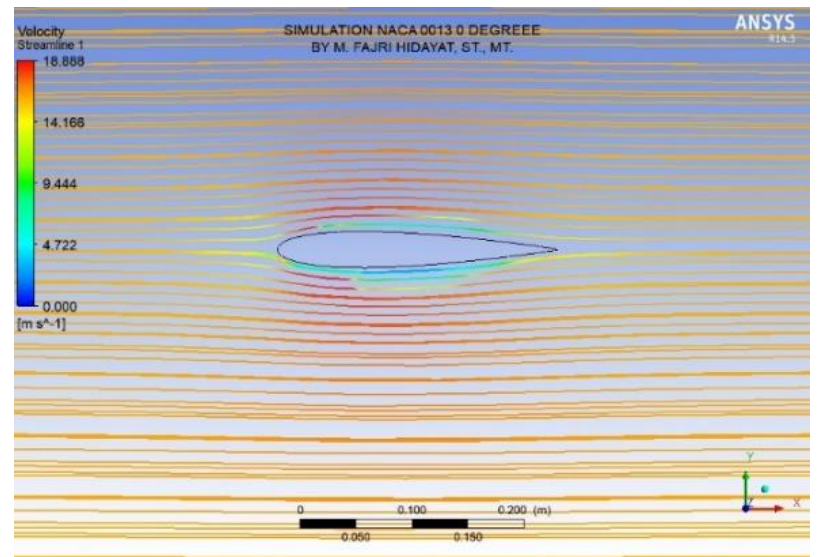

Gambar 2 Distribusi Kecepatan Airfoil NACA 0013 dengan ANSYFFluent

\section{Metodologi Penelitian}

Dalam penelitian ini menggunakan metode CFD (Computational Fluid Dynamics), dimana urutan proses dari Pemodelan hingga menghasilkan gambar kontur distribusi tekanan dapat diuraikan sebagai berikut :

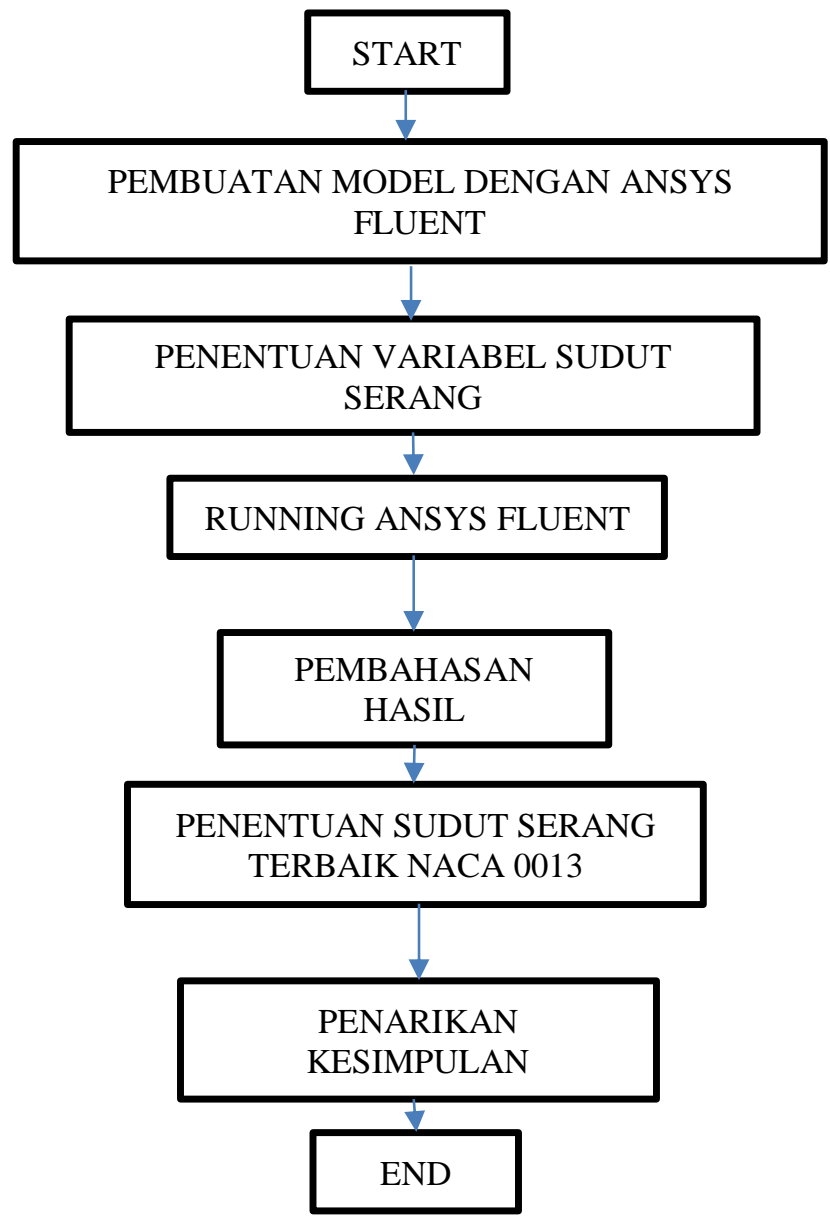

Gambar 3 Flowcart Penelitian

Tabel 2. Dimensi Model NACA 0013

\begin{tabular}{|c|c|c|c|c|c|}
\hline $\begin{array}{c}\text { Type } \\
\text { NACA }\end{array}$ & $\begin{array}{c}\text { Maximum } \\
\text { Thickness } \\
(\mathrm{mm})\end{array}$ & $\begin{array}{c}\text { Chord } \\
\text { Length } \\
(\mathrm{mm})\end{array}$ & $\begin{array}{c}\text { Span } \\
(\mathrm{mm})\end{array}$ & $\begin{array}{c}\text { Location } \\
\text { of } \\
\text { Maximum } \\
\text { Thickness } \\
(\mathrm{mm})\end{array}$ & $\begin{array}{c}\text { Weight } \\
(\text { Gram })\end{array}$ \\
\hline 0013 & 32,5 & 250 & 445 & 75 & 110 \\
\hline
\end{tabular}

Tabel 3. Data Input Kecepatan dan Tekanan Udara

\begin{tabular}{|c|c|c|c|c|}
\hline $\begin{array}{c}\mathrm{T} \\
\left({ }^{\circ} \mathrm{C}\right)\end{array}$ & $\begin{array}{c}\rho \\
\left(\mathrm{Kg} / \mathrm{m}^{3}\right)\end{array}$ & $\begin{array}{c}\mathrm{V} \\
(\mathrm{m} / \mathrm{s})\end{array}$ & $\begin{array}{c}v \\
\left(\mathrm{~m}^{2} / \mathrm{s}\right)\end{array}$ & $\begin{array}{c}\mathrm{P} \\
(\mathrm{kPa})\end{array}$ \\
\hline 30,8 & 1,161 & 16 & $\times 10^{-5}$ & 101,325 \\
\hline
\end{tabular}

Tabel 4. Variasi Sudut Serang

\begin{tabular}{|c|c|c|c|c|c|c|c|c|}
\hline$\alpha_{1}$ & $\alpha_{2}$ & $\alpha_{3}$ & $\alpha_{4}$ & $\alpha_{5}$ & $\alpha_{6}$ & $\alpha_{7}$ & $\alpha_{8}$ & $\alpha_{9}$ \\
\hline $0^{\circ}$ & $3^{\mathrm{o}}$ & $6^{\mathrm{o}}$ & $9^{\mathrm{o}}$ & $12^{\mathrm{o}}$ & $15^{\mathrm{o}}$ & $18^{\mathrm{o}}$ & $21^{\mathrm{o}}$ & $24^{\mathrm{o}}$ \\
\hline
\end{tabular}

\section{Temuan dan Pembahasan}

Dari Simulasi CFD dengan ANSYS-Fluent didapatkan Kontur Tekanan dari 9 Variabel sudut serang tersebut sebagai berikut: 


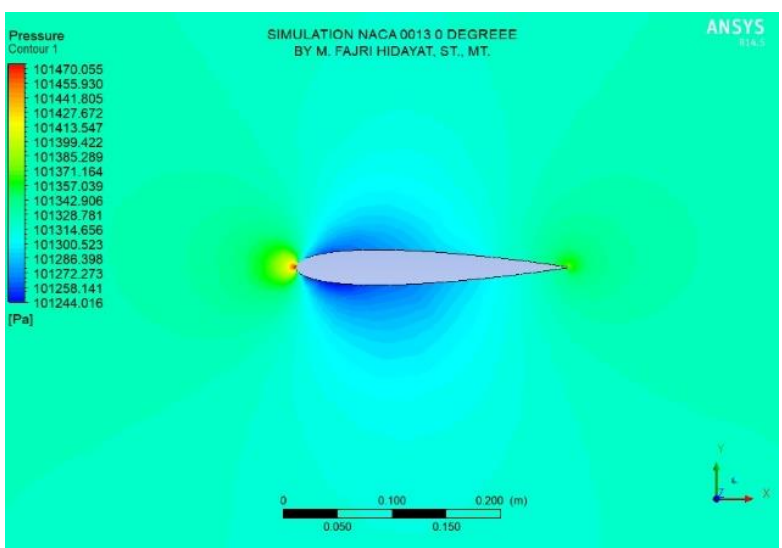

Gambar 4 Kontur Tekanan pada $\mathrm{O}^{\circ}$

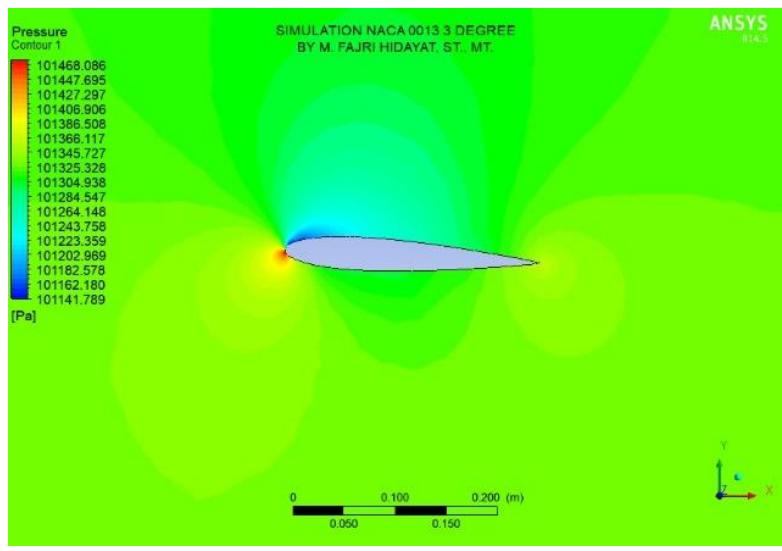

Gambar 5. Kontur Tekanan pada $3^{\circ}$

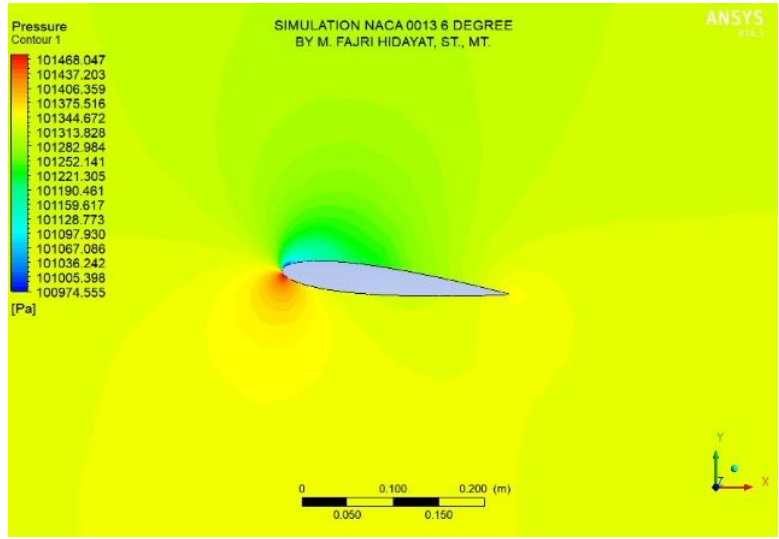

Gambar 6. Kontur Tekanan pada $6^{\circ}$

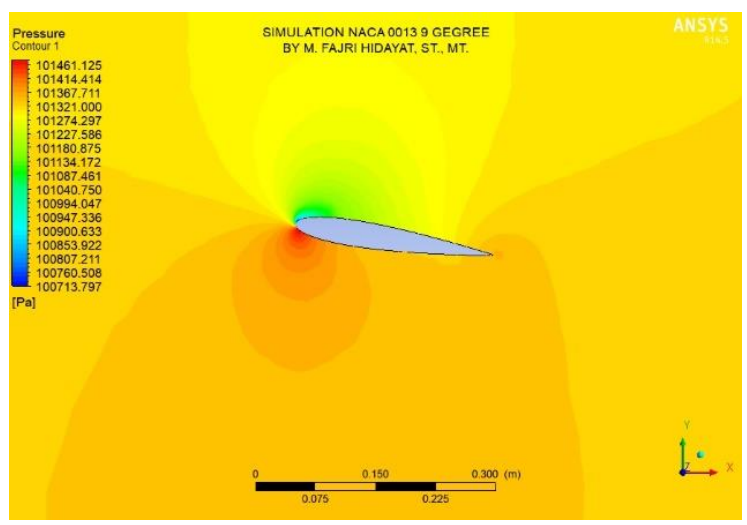

Gambar 7. Kontur Tekanan pada $9^{\circ}$

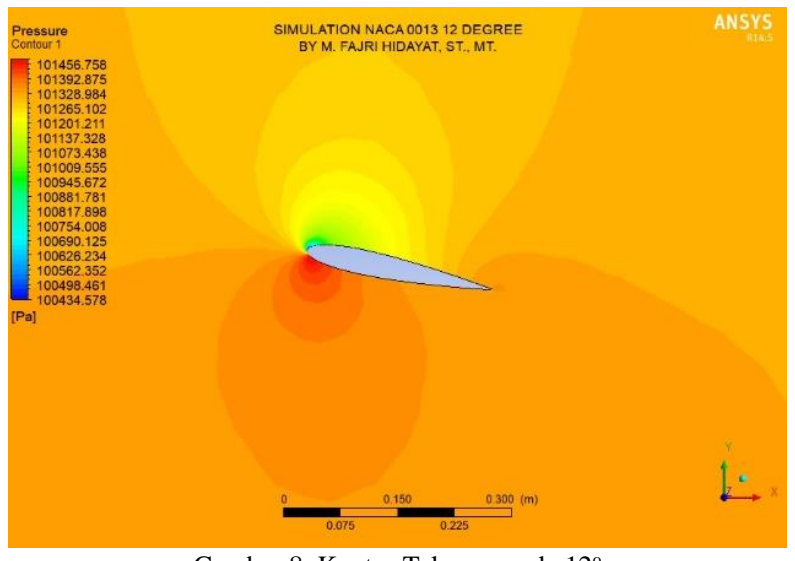

Gambar 8. Kontur Tekanan pada $12^{\circ}$

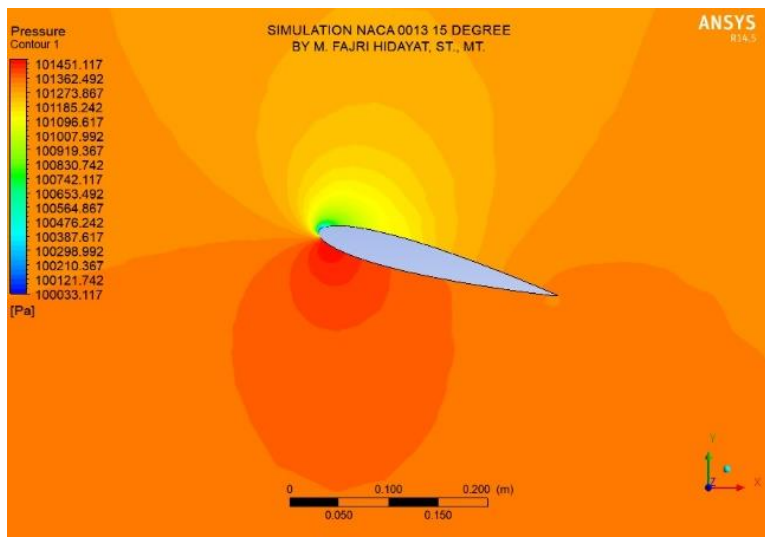

Gambar 9. Kontur Tekanan pada $15^{\circ}$

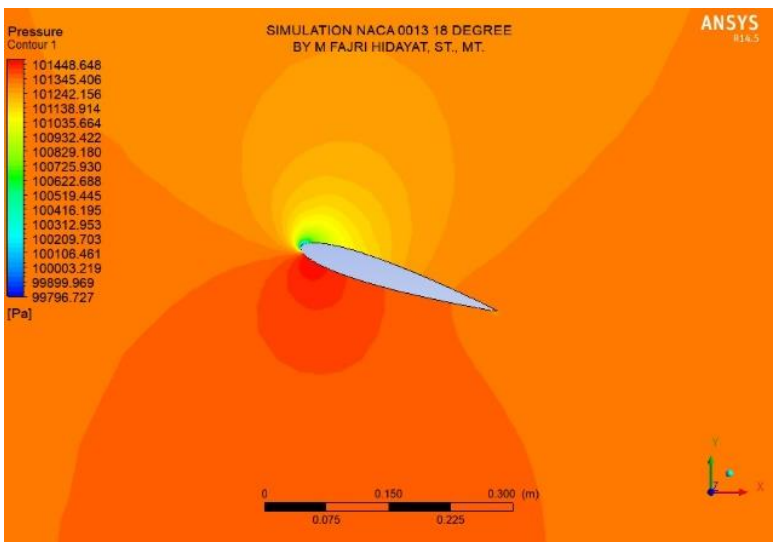

Gambar 10. Kontur Tekanan pada $18^{\circ}$

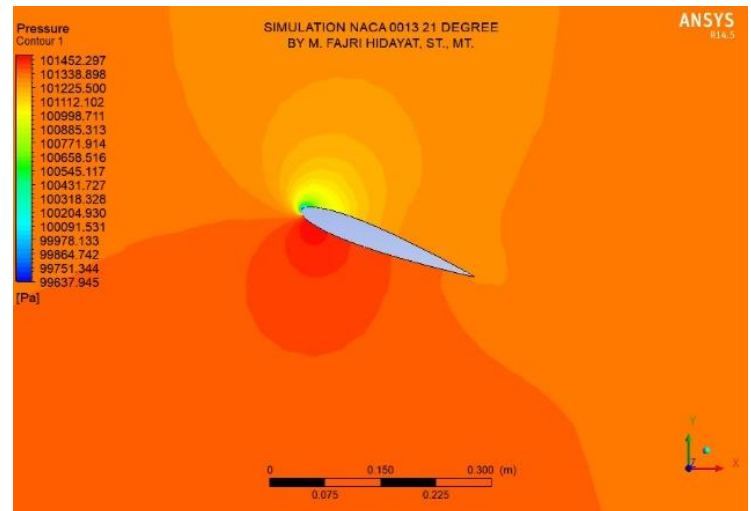

Gambar 11. Kontur Tekanan pada $21^{\circ}$

Seminar Nasional TEKNOKA ke - 3, Vol. 3, 2018 ISSN No. 2502-8782 




Gambar 12. Kontur Tekanan pada $24^{\circ}$

Dari gambar hasil tersebut diatas dapat ditarik pembahasan sebagai berikut :

1. Penambahan besarnya sudut serang sedikit demi sedikit dari $0^{\circ}, 3^{\circ}$ hingga $18^{\circ}$ menunjukkan trend kenaikan harga Lift.

2. Dan mencapai puncak harga Lift tertinggi pada sudut serang $21^{\circ}$.

3. Kemudian harga Lift menurun sedikit demi sedikit. Harga Lift tertinggi inilah yang dipakai untuk menentukan sudut serang pesawat saat Take Off.

Dari proses Running dan Calculation di Fluent, didapatkan harga Gaya Lift untuk masing-masing sudut serang sebagai berikut :

Tabel 5. Harga Gaya Lift

\begin{tabular}{|c|c|}
\hline Angle of Attack ( $\mathbf{(}^{\circ}$ & Lift (N) \\
\hline 0 & 3,195 \\
\hline 3 & 16,028 \\
\hline 6 & 26,478 \\
\hline 9 & 37,670 \\
\hline 12 & 46,688 \\
\hline 15 & 54,474 \\
\hline 18 & 59,171 \\
\hline $\mathbf{2 1}$ & $\mathbf{6 1 , 6 5 0}$ \\
\hline 24 & 59,481 \\
\hline
\end{tabular}

Dari tabel diatas kemudian dibuat Grafik Harga Lift terhadap Sudut Serang seperti yang digambarkan pada grafik di bawah ini :

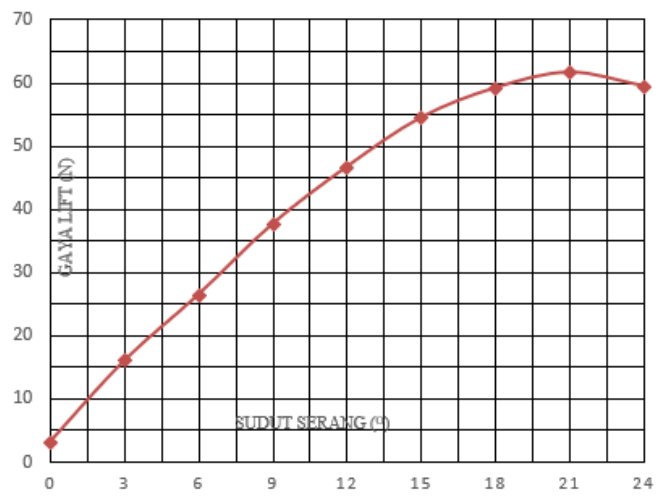

Gambar 13. Grafik Gaya Lift terhadap Sudut Serang

\section{Simpulan}

Dari penelitian ini dapat diambil kesimpulan sebagai berikut:

a. Harga Gaya Lift semakin naik mendekati linier pada sudut serang $0^{\circ}$ hingga $18^{\circ}$ hal ini menunjukkan bahwa tekanan udara di sebelah bawah permukaan airfoil lebih tinggi dari tekanan udara permukaan airfoil sebelah atas yang menyebabkan airfoil terangkat dan masih menunjukkan tren yang masih stabil walaupun semakin besar sudut serang menunjukkan adanya gaya vortex di ujung belakang airfoil semakin membesar.

b. Harga Gaya Lift mencapai puncak yaitu sebesar 61,650 $\mathrm{N}$ pada sudut serang $21^{\circ}$ kemudian menurun pada sudut serang $24^{\circ}$ hal ini diakibatkan oleh semakin besarnya vortex di bagian ujung belakang airfoil yaitu adanya aliran yang mulai acak dan tidak beraturan yang mengganggu terangkatnya pesawat secara stabil.

c. Sebagai referensi bagi industri pesawat terbang, maka harga sudut serang $21^{\circ}$ ini bisa dipakai pada saat pesawat Take Off untuk tipe airfoil NACA 0013.

Sebagai saran, Airfoil NACA 0013 ini bisa direkomendasikan sebagai tipe sayap pesawat penumpang komersil di industri pesawat terbang nusantara kedepannya karena memiliki ketebalan yang relatif kecil (tipis) dan ruang pemilihan sudut serang yang besar

\section{Kepustakaan}

[1] Frank M. White, Fluid Mechanics, University of Rhode Island, 4th edition, Mc. GrawHill, Boston,1997, p.471.

[2] Edward J. Shaughessy, Jr., Ira M. Katz, James P. Schaffer, Introduction to Fluid Mechanics, Oxford University Press, New York, 2005, p.770.

[3] Anderson, John D., Jr., Fundamentals of Aerodinamics, McGrawHill Book Company, Boston, 2001, p.283.

[4] Lennon, Andy, RC Model Aircraft Design, Air Age Media Inc., New York, 2005, p.6.

[5] Abbott, Ira, Theory of Wing Sections, Including a Summary of Airfoil Data, Dover Publications, New York, 1959, p.113.

[6] Kondapalli Siva Prasad, Vommi Krishna, B.B. Ashok Kumar, J. Aerospace. Eng. \& Tech., JAET, 3 (2015) 2.

[7] Mayurkymar Kevadiya, International Journal of Eng. Trends and Tech., IJETT, 4 (2013) 5.

[8] Mayurkumar Kevadiya, Hemish A. Vaidya, Int. Journal of Innovative Research in Science Eng. and Tech., IJIRSET, 2 (2013) 5.

[9] James Julian, Harinaldi, Budiarso, Revan Difitro, Parker Stefan, Int Journal of Tech., IJTech, 2 (2016) 306.

[10] Kang Pyo Cho, Seung Hwan Jeong, Dany Perwita Sari, Int. Journal of Tech., IJTech, 3 (2011) 189.

[11] Musavir Bashir, S.A. Khan, Qummare Azam, Ayub Ahmed Janvekar, Int. Journal of Tech., IJTech, 3 (2017) 366 